\title{
EVALUASI TATA KELOLA TEKNOLOGI INFORMASI DENGAN METODE COBIT 4.0 DOMAIN DS DAN ME PADA PT CENTRA GLOBAL INVESTAMA JAKARTA
}

\author{
Sabtoadhy Bagus Pambudi ${ }^{1}$, Rani Irma Handayani ${ }^{2}$, Dinar Ajeng Kristiyanti ${ }^{3}$
}

${ }^{1}$ Sistem Informasi, Sekolah Tinggi Manajemen Informatika dan Komputer Nusa Mandiri

${ }^{2}$ Sistem Informasi, Universitas Bina Sarana Informatika

${ }^{3}$ Teknik Informatika, Sekolah Tinggi Manajemen Informatika dan Komputer Nusa Mandiri e-mail: sbagus.pambudi@gmail.com ${ }^{1}$, rani.rih@bsi.ac.id² ${ }^{2}$ dinar@nusamandiri.ac.id ${ }^{3}$

\begin{abstract}
Abstrak
Penggunaan teknologi informasi sudah menjadi kebutuhan pokok bagi masyarakat saat ini dalam berbagai kegiatan komunikasi dan bisnis. Hampir setiap individu maupun institusi menerapkan teknologi informasi sebagai alat penunjang kegiatan komunikasi dan bisnis. Bagi institusi, penerapan teknologi informasi memerlukan biaya investasi yang tidak sedikit. Selain investasi dalam hal logistik, sumber daya manusia juga menjadi faktor penentu dalam keefektifan dan efisiensi keberlangsungan perusahaan. Evaluasi tata kelola teknologi informasi perlu dilakukan pada PT Centra Global Investama Jakarta. Dalam penelitian ini metode COBIT 4.0 (Control Objective for Information and Related Technology) dengan pendekatan domain DS (Delivery and Support) dan ME (Monitoring and Evaluation) dipilih untuk direkomendasi sebagai dasar pengelolaan teknologi informasi. Dari pemetaan model maturity tersebut diperoleh bahwa tingkat maturity untuk PT Centra Global Investama Jakarta sudah sesuai harapan berada pada level 3. Namun perlu dilakukan upaya untuk menutupi gap agar tingkat maturity dari masing-masing control process tersebut dapat berjalan lebih optimal dan berkembang.
\end{abstract}

Kata kunci: COBIT, Pemantauan dan Evaluasi, Pengiriman dan Dukungan, Tata Kelola $\mathrm{TI}$

\section{Abstract}

The use of information technology at the present time have become important need requirement for peoples to do various activities of communication and the business. Almost every people although institution who apply all the core subjects of information technology as a tool to support the good communication and the business. The application of information technology requires a fee investment which should not be failed not in the least for institution. In addition to investment in terms of logistics, human resources are also to be the chief factor determining if effectiveness and efficiencies of the persistence of the company. Evaluation carried out by the need to be undertaken governance reform projects for PT Centra Global Investama Jakarta through the information and technology. In this research a method of COBIT 4.0 (Control Objectives for Information and related Technology) with the approach the domain of DS (Delivery and Support) and ME (Monitoring and Evaluation) was chosen to recommend as a basis governance use of information technology. From the mapping of a maturity model were obtained that maturity of PT Centra Global Investama Jakarta had been suitable there are on level 3. Therefore it need to attempts gap covering of maturity level of each control process so it can walk optimally and institution can be developing.

Keywords : COBIT, Monitoring and Evaluation, Delivery and Support, IT Governance 


\section{PENDAHULUAN}

Dalam pelaksanaan kegiatan komunikasi dan bisnis, penggunaan teknologi informasi bukan lagi hal yang asing bagi masyarakat saat ini. Hampir setiap individu maupun institusi menerapkan teknologi informasi sebagai alat yang dipercaya mampu meningkatkan efisiensi proses kegiatan komunikasi dan bisnis.

Dalam menjalankan bisnisnya, sebuah perusahaan dituntut untuk memberikan kualitas pelayanan yang terbaik bagi konsumen [1]. Menjaga kualitas layanan teknologi informasi bagi penyedia layanan internet atau biasa dikenal dengan ISP (Internet Service Provider) adalah hal yang sangat penting agar dapat mendukung kecepatan, kemudahan dan kenyamanan dalam layanannya. Dalam era perkembangan teknologi informasi saat ini PT Centra Global Investama Jakarta memiliki peluang yang sama untuk berlomba mengembangkan strategi bisnis yang baik, salah satunya dengan memanfaatkan kemajuan teknologi informasi dalam jasa pelayanan. Konsep dari pembuatan teknologi informasi pada suatu organisasi mempunyai tujuan agar dapat bekerja secara efisien pada komputer yang digunakan dan mendapatkan nilai ekonomis, sehingga hasil keluaran (output) akan membawa banyak keuntungan bagi organisasi itu sendiri [2].

Sehubungan dengan peluang tersebut, [3] berpendapat bahwa pengelolaan layanan teknologi informasi secara efisien dan efektif akan mendukung tingkat pelayanan yang diberikan kepada pelanggan. Namun dalam pelaksanaannya, penerapan teknologi informasi memerlukan biaya investasi yang tidak sedikit. Untuk mengatasi hal tersebut perlu adanya kesinambungan dalam pengelolaan, agar tata kelola teknologi informasi yang sesuai dapat menjadikan suatu kebutuhan yang mendasar. Sehingga diharapkan peningkatan peran teknologi informasi nantinya harus berbanding lurus dengan hasil kerja yang dikeluarkan yang biasanya hasil yang dikeluarkan sangat kompleks [4].
Dalam upaya pengoptimalan dan pengembangan kualitas layanan sistem informasi, serta untuk mengetahui korelasi strategi bisnis organisasi dengan peran teknologi informasi maka perlu dilakukan analisis terhadap penerapan layanan sistem informasi dan tata kelola teknologi informasi pada PT Centra Global Investama Jakarta. Berdasarkan hal tersebut maka dapat dirumuskan permasalahan diantaranya bagaimana pelaksanaan sistem informasi dan tata kelola teknologi informasi pada PT Centra Global Investama Jakarta dengan kerangka kerja COBIT, khususnya dengan domain Delivery and Support dan Monitoring and Evaluation, bagaimana tingkat kematangan sistem informasi dan tata kelola teknologi informasi pada PT Centra Global Investama Jakarta dengan kerangka kerja COBIT, khususnya dengan domain Delivery and Support dan Monitoring and Evaluation, serta terakhir adalah bagaimana cara perbaikan sistem informasi dan tata kelola teknologi informasi pada PT Centra Global Investama Jakarta dengan kerangka kerja COBIT, khususnya dengan domain Delivery and Support dan Monitoring and Evaluation.

Berdasarkan hal tersebut maka perlu dilakukan pengkajian dan evaluasi terhadap penerapan tata kelola teknologi informasi pada PT Centra Global Investama Jakarta dengan menggunakan framework COBIT, kemudian membuat sebuah rekomendasi pengelolaan teknologi informasi yang sesuai dengan strategi bisnis dan tujuan PT Centra Global Investama Jakarta berdasarkan KGI (Key Goals Indicators) dan KPI (Key Performance Indicator).

Dengan demikian dapat dikemukakan hipotesis mengenai hal tersebut, diantaranya $\mathrm{H}_{0}$ dan $\mathrm{H}_{1}$. Dimana $\mathrm{H}_{0}$ mengidentifikasian masalah tingkat kematangan pelaksanaan tata kelola teknologi informasi pada PT Centra Global Investama Jakarta saat ini berada pada level 2. Sedangkan $\mathrm{H}_{1}$ berisi berdasarkan identifikasi masalah tingkat kematangan pelaksanaan tata kelola teknologi informasi pada PT Centra Global Investama Jakarta berada pada level lebih besar dari level 2 . 


\section{METODE}

Tata kelola secara harfiah berarti mengendalikan yang berkaitan kepemerintahan, perusahaan dan lain sebagainya. Disamping tata kelola sering dilihat sebagai penerapan perilaku bisnis, menurut [5] tata kelola di definisikan sebagai sekumpulan tanggung jawab dan praktik yang dilaksanakan oleh dewan dan manajemen eksekutif dengan tujuan memberikan arahan strategis, memastikan tujuan dapat dicapai, memastikan resiko dapat dikelola dengan tepat dan membuktikan sumber daya perusahaan digunakan dengan tanggung jawab. [6] Menerangkan bahwa The Australian Standard for Corporate Governance of Information and Communication Technology (Standar Australia untuk Tata Kelola Perusahaan Teknologi Informasi dan Komunikasi) mendefinisikan Tata Kelola Perusahaan TIK sebagai sistem penggunaan TIK saat ini dan masa depan yang diarahkan dan dikendalikan, termasuk mengevaluasi dan mengarahkan rencana penggunaan TIK untuk mendukung organisasi dan memantau penggunaan TIK untuk mencapai rencana, termasuk strategi dan kebijakan menggunakan TIK dalam sebuah organisasi. Munculnya perangkat multitasking yang disertai dengan peningkatan secara simultan bersamaan aliran informasi melalui jaringan komunikasi, kemudian saat ini dikenal dengan teknologi informasi. Terkait hal tersebut, dalam penelitiannya [7] mengemukakan teknologi informasi merupakan salah satu aspek penting dari tata kelola organisasi secara keseluruhan. Sehingga pengelolaan teknologi informasi yang baik akan menjamin efisiensi dan pencapaian kualitas layanan yang baik bagi tujuan, dalam hal ini bertujuan bagi organisasi.

Definisi dari audit adalah mengumpulkan dan mengevaluasi buktibukti bagaimana sistem informasi dikembangkan, dioperasikan, diorganisasikan, serta bagaimana praktek dilaksanakan. Memastikan bahwa agar sistem informasi melindungi aset institusi, integritas data dan sistem diproteksi secara cukup, dan operasi sistem yang efektif dan efisien dalam mencapai tujuan organisasi. Dalam bukunya, [8] berpendapat IT audit perlu me-review pemantauan terhadap kinerja perangkat vital utamanya pemantauan terhadap kinerja server, dan status aktifasi koneksi jaringan. Untuk memastikan pemantauan terhadap kinerja perangkat vital dilaksanakan secara konsisten. Menurut [9] audit sistem informasi merupakan proses pengumpulan dan pengevaluasian bukti untuk menentukan apakah sistem informasi telah menetapkan dan menerapkan sistem pengendalian internal yang memadai, semua aset dilindungi dengan baik dan tidak disalahgunakan serta terjaminnya integritas data, keandalan serta efektifitas dan efisiensi penyelenggaraan sistem informasi berbasis komputer.

Secara garis besar COBIT adalah a set of best practice (framework) bagi pengelolaan teknologi inofrmasi yang secara lengkap terdiri dari: executive primary, framework, control objectives, audit guidelines, implementation tool set serta management guidelines yang sangat berguna untuk proses sistem informasi strategis. Dalam bukunya, [6] berpendapat bahwa Control Objectives for Information and related Technology (COBIT) adalah kerangka kerja untuk mengembangkan, menerapkan, memantau, dan memperbaiki tata kelola dan praktik manajemen teknologi informasi. [10] pun memiliki pendapat yang serupa bahwa Control Objective for Information and Related Technology (COBIT) adalah kerangka kerja yang dibuat oleh Information System Audit and Control Association (ISACA) untuk manajemen teknologi informasi dan IT governance sebagai alat pendukung yang memungkinkan manajer untuk menjembatani kesenjangan antar kebutuhan kontrol, masalah teknis dan resiko bisnis. 
Peneliti menggunakan kerangka kerja untuk mengembangkan, menerapkan, memantau dan memperbaiki tata kelola dan praktik manajemen teknologi informasi yaitu Control Objectives for Information and related Technology (COBIT) [6] dengan versi yang digunakan adalah COBIT 4.0. Adapun domain yang peneliti gunakan ada 2 (dua) domain dengan masing-masing aspek yang terdapat di kedua domain tersebut diantaranya:

\section{Delivery and Support}

Domain Delivery and Support, sesuai dengan namanya, domain ini memberikan fokus utama pada aspek penyampaian atau pengiriman dari teknologi informasi. Seperti yang dikemukakan oleh [10], domain ini (Delivery and Support) mencakup area-area seperti pengoperasian aplikasi-aplikasi dalam sistem teknologi informasi dan hasilnya, dan juga proses dukungan yang memungkinkan pengoperasian sistem teknologi informasi tersebut dengan efektif dan efisien.

\section{Monitoring and Evaluation}

Selanjutnya domain Monitoring and Evaluation, semua proses teknologi informasi perlu dinilai secara teratur sepanjang waktu untuk menjaga kualitas dan pemenuhan atas syarat pengendalian. Dalam penelitiannya [10] mengemukakan domain ini (Monitoring and Evaluation) menunjuk pada aspek perlunya pengawasan manajemen atas proses pengendalian dalam organisasi, serta penilaian independen yang dilakukan baik auditor internal maupun eksternal atau diperoleh dari sumber-sumber alternatif lainnya.

Dalam penelitian ini tahapan yang dilakukan sebagai evaluasi tata kelola teknologi informasi dengan metode Control Objectives for Information and related Technology (COBIT) 4.0 domain Delivery and Support dan Monitoring and Evaluation studi kasus PT Centra Global Investama Jakarta dijelaskan secara umum sebagai berikut:
1. Survey Literatur

Pada tahap awal ini peneliti melakukan pencarian materi, pembuatan draf kuesioner, serta mempelajari sistem informasi yang ada di perusahaan.

2. Identifikasi Masalah

Memulai proses penelitian dengan mengidentifikasi secara langsung tentang masalah yang akan dibahas, berkaitan dengan evaluasi tata kelola teknologi informasi dengan metode Control Objectives for Information and related Technology (COBIT) 4.0 domain delivery and support dan monitoring and evaluation studi kasus PT Centra Global Investama Jakarta berdasarkan literatur dan informasi yang diperoleh.

\section{Studi Pustaka}

Peneliti mempelajari literatur berupa tulisan-tulisan jurnal dan buku berkaitan dengan teori tentang tata kelola teknologi informasi dan COBIT yang akan digunakan sebagai kajian teori dalam penelitian.

4. Hipotesis

Berdasarkan identifikasi masalah dan studi pustaka terkait, peneliti memiliki hipotesis sebagai berikut:

a. Pengidentifikasian masalah tingkat kematangan pelaksanaan tata kelola teknologi informasi pada PT Centra Global Investama Jakarta saat ini berada pada level 2 .

b. Berdasarkan identifikasi masalah tingkat kematangan pelaksanaan tata kelola teknologi informasi pada PT Centra Global Investama Jakarta berada pada level lebih besar dari level 2.

5. Menentukan Variabel dan Sumber Data

Peneliti menentukan variabel-variabel dari evaluasi tata kelola teknologi informasi dengan metode Control Objectives for Information and related Technology (COBIT) 4.0 domain delivery and support dan monitoring and evaluation studi kasus PT Centra Global Investama Jakarta dengan berdasarkan model tingkat kematangan (maturity level) yang akan dituangkan dalam 
kuesioner, kemudian menentukan subjek penelitian.

Adapun variabel-variabel maturity level yang terdapat pada domain Delivery and
Support dan Monitoring and Evaluation sebagai berikut.

Tabel 1. Variabel Domain Delivery and Support

\begin{tabular}{ll}
\hline DS1 & Mendefinisikan dan Mengelola Tingkat Layanan \\
DS2 & Mengelola Pelayanan dari Pihak Ketiga \\
DS3 & Mengatur Kinerja dan Kapasitas \\
DS4 & Menjamin Keberlangsungan Pelayanan \\
DS5 & Menjamin Keamanan Sistem \\
DS6 & Mengidentifikasi dan Mengalokasikan Biaya \\
DS7 & Memberikan Pelatihan dan Pendidikan Pada User \\
& Tabel 2. Variabel Domain Monitoring and Evaluation \\
\hline ME1 & Mengawasi dan Mengevaluasi Kinerja Teknologi Informasi \\
ME2 & Menaawasi dan Menaevaluasi Kontrol Internal \\
ME3 & Menjamin Kepatuhan Hukum \\
ME4 & Membuat Tata Kelola Teknologi Informasi \\
\hline
\end{tabular}

6. Observasi Lapangan dan Perizinan

Peneliti secara langsung datang ke PT

Centra Global Investama Jakarta dan meminta izin kepada pihak-pihak terkait yang berwenang dalam penelitian ini adalah direktur utama PT Centra Global Investama Jakarta.

7. Mengumpulkan Data

Peneliti mengumpulkan data dengan melakukan wawancara kepada direktur utama PT Centra Global Investama Jakarta dan memberikan kuesioner kepada beberapa sampel untuk mendapatkan data yang dibutuhkan.

8. Pengolahan Data Menggunakan Metode COBIT

Dalam pengolahan data akan digunakan suatu ukuran yang sudah ditentukan oleh COBIT yaitu dengan melihat tingkat kematangan (maturity level) proses agar situasi yang diinginkan dapat di ukur.

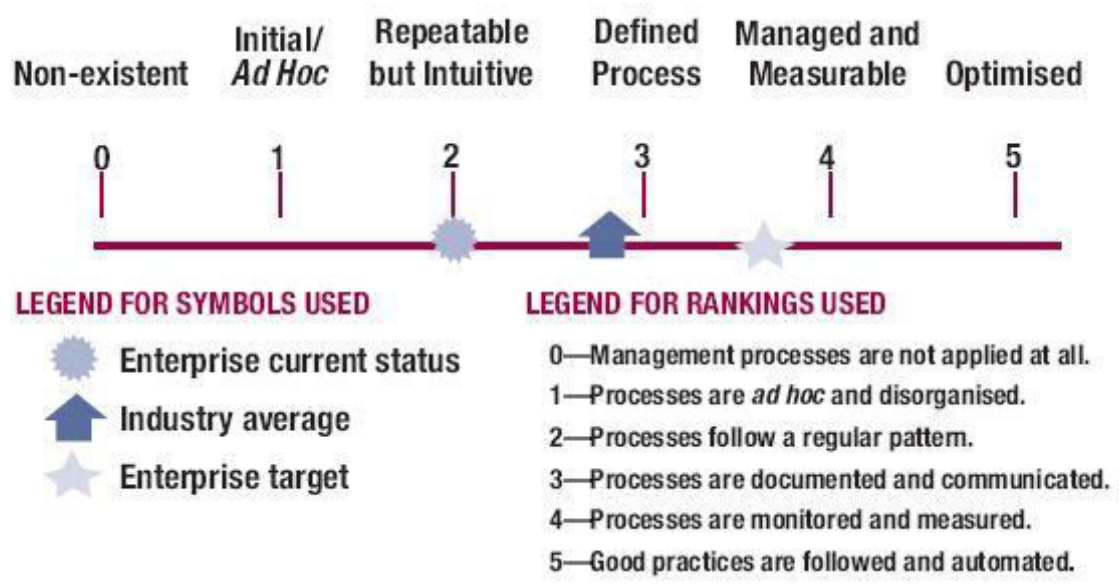

Gambar 1. Grafik Representasi Maturity Model (Sumber, ITGI 2007) 
Pendefinisian model kematangan proses teknologi informasi mengacu pada kerangka kerja COBIT dengan proses yang akan ditinjau agar dalam tata kelolanya lebih dioptimalkan secara umum sebagai berikut:

Tabel 3. Model Kematangan (Maturity Level) COBIT

\begin{tabular}{|c|c|}
\hline Level & Kriteria Kematangan \\
\hline Level 0 & $\begin{array}{l}\text { Tidak ada (Non-Existent) } \\
\text { Kekurangan yang menyeluruh terhadap proses apapun yang } \\
\text { dapat dikenali. Organisasi bahkan tidak mengetahui terdapat } \\
\text { permasalahan yang harus diatasi. }\end{array}$ \\
\hline Level 1 & $\begin{array}{l}\text { Inisialisasi (Initial) } \\
\text { Terdapat bukti bahwa organisasi mengetahui permasalahan } \\
\text { yang harus diatasi. Bagaimanapun juga tidak terdapat proses } \\
\text { standar, namun menggunakan pendekatan ad hoc yang } \\
\text { cenderung diperlakukan secara individu atau per kasus. } \\
\text { Secara umum pendekatan kepada pengelola tidak terorganisir. }\end{array}$ \\
\hline Level 2 & $\begin{array}{l}\text { Berulang tapi Intuitif (Repeatable but intutive) } \\
\text { Proses dikembangkan kedalam tahapan prosedurnya yang } \\
\text { serupa namun tidak seluruhnya terdokumentasi dan tidak } \\
\text { seluruhnya disosialiasasikan kepada pelaksana. Belum ada } \\
\text { pelatihan formal untuk mensosialisasikan prosedur tersebut } \\
\text { dalam komunikasi prosedur standar dan tanggung jawab } \\
\text { pelaksana pada masing-masing individu. Terdapat tingkat } \\
\text { kepercayaan yang tinggi terhadap kemampuan individu } \\
\text { sehingga kemungkinan error sangat besar. }\end{array}$ \\
\hline Leve & $\begin{array}{l}\text { Proses Terdefinisi (Defined Process) } \\
\text { Prosedur telah distandarisasikan dan didokumentasikan, dan } \\
\text { dikomunikasikan melalui pelatihan. Kemudian tahapan tersebut } \\
\text { telah memiliki prosedur dan standar formal dan tertulis yang } \\
\text { telah disosialisasikan ke segenap jajaran manajemen dan } \\
\text { karyawan untuk dipatuhi dan dikerjakan dalam aktifitas. } \\
\text { Prosedur dikembangkan tanpa adanya pengawasan } \\
\text { memungkinkan terjadinya banyak penyimpangan. }\end{array}$ \\
\hline Level 4 & $\begin{array}{l}\text { Terkelola dan Terukur (Managed and Measurable) } \\
\text { Manajemen telah memiliki sejumlah indikator atau ukuran } \\
\text { kepatutan dalam prosedur yang sudah berjalan, yang dapat } \\
\text { mengambil tindakan jika terdapat proses yang diindikasikan } \\
\text { tidak efektif. Proses diperbaiki terus-menerus dan } \\
\text { dibandingkan dengan praktik-praktik terbaik. Terdapat } \\
\text { perangkat bantu dan otomatisasi untuk pengawasan proses. }\end{array}$ \\
\hline
\end{tabular}




Level 5 Optimal (Optimised)
Proses telah mengimplentasikan tata kelola manajemen
teknologi informasi yang mengacu pada praktik terbaik. Proses
telah mencapai level terbaik karena perbaikan yang terus
menerus dan perbandingan dengan perusahaan lain.
Teknologi informasi telah digunakan sebagai perangkat bantu
otomatis digunakan untuk mendukung workflow, menambah
efisiensi dan kualitas kerja, proses, serta memudahkan
perusahaan untuk beradaptasi terhadap perubahan.

9. Menarik Kesimpulan

Peneliti menarik sebuah kesimpulan berdasarkan analisis data pada beberapa bab sebelumnya, kemudian memeriksa apakah kesimpulan sesuai dengan hipotesis, maksud dan tujuan penelitian. Selain itu memberikan saran yang dapat digunakan sebagai masukan bagi perusahaan terkait untuk dapat dimanfaatkan lebih lanjut.

Dalam upaya mendapatkan data yang akurat, peneliti menggunakan 2 metode pengumpulan data, yaitu:

a. Data primer dengan menggunakan observasi langsung dan wawancara.

1) Observasi

Peneliti melakukan serangkaian pengumpulan data dengan mendatangi PT Centra Global Investama Jakarta untuk mengamati langsung terhadap subjek atau objek penelitian.

2) Wawancara

Wawancara dengan direktur sekaligus manager project PT Centra Global Investama Jakarta, tujuannya untuk mendapatkan informasi dan data yang berkaitan dengan penelitian secara akurat.

b. Data sekunder diperoleh dengan mengumpulkan dan mengidentifikasi data, yang kemudian di olah dengan menyertakan data tertulis berdasarkan referensi beberapa buku dan jurnal yang berkaitan dengan penelitian.

\section{HASIL DAN PEMBAHASAN}

Pengumpulan data dilakukan dengan wawancara bersama direktur PT Centra
Global Investama Jakarta untuk mengetahui sejarah perusahaan, latar belakang perusahaan dan proses berjalannya perusahaan, khususnya dalam hal tata kelolanya. Pengumpulan data juga dilakukan dengan penyebaran kuesioner berstandar COBIT ke beberapa sampel pada kantor PT Centra Global Investama Jakarta yang meliputi bagian manajemen tingkat atas (top level management) yang terdiri dari direktur dan manajer, dan manajemen tingkat bawah (low level management) yang terdiri dari supervisor engineer dan supervisor network operator center Adapun pertimbangan-pertimbangan yang sesuai dengan kriteria dalam pemilihan sampel, diantaranya:

1. Sampel yang dipilih merupakan sampel yang memahami penerapan manajemen teknologi informasi pada PT Centra Global Investama Jakarta.

2. Sampel yang dipilih merupakan direktur, manajer, dan supervisor pada PT Centra Global Investama Jakarta.

Pada penentuan skoring kriteria kuesioner, peneliti menggunakan skala Gutman yang merefleksikan pola jawaban dengan nilai minimal 0 (nol) untuk jawaban 'Tidak' dan nilai maksimal 1 (satu) untuk jawaban 'Ya'. Berdasarkan ketentuan tersebut maka data yang diperoleh dari hasil penyebaran kuesioner diberikan nilai dengan skala Gutman.

Dalam tahap analisis agar dapat data di interpretasikan, analisis data penelitian ini dibagi menjadi 3 bagian, yaitu:
1. Analisis Tingkat Kematangan
Keadaan Saat Ini (current maturity) 
Analisa kuesioner terhadap tingkat kematangan tata kelola teknologi informasi sesuai dengan keadaan saat ini diberi bobot $0-5$, kemudian dilakukan rekapitulasi jawaban yang menggambarkan prosentase tiap jawaban. Kemudian menghitung nilai masing-masing level maturity model dengan cara membagi jumlah jawaban dengan jumlah responden tiap proses teknologi informasi, rumus dituliskan sebagai berikut:

$$
\text { Index Maturity }=\frac{\text { Jumlah Jawaban }}{\text { Jumlah Responden }}
$$

Index maturity yang di dapat kemudian dibuat ke dalam skala yang akan dipetakan lagi ke dalam maturity level untuk mengetahui tingkat kematangannya.

$$
\begin{array}{llll}
\text { 2. Analisis Tingkat } & \multicolumn{2}{c}{\text { Kematangan }} \\
\text { Keadaan Yang Ingin Dicapai } \\
\text { (expected maturity) }
\end{array}
$$

Proses analisis tingkat kematangan yang diharapkan adalah dengan adanya prosedur yang distandarisasikan, didokumentasikan, dan dikomunikasikan melalui pelatihan. Berdasarkan kriteria tersebut ditentukan sesuai kriteria kematangan yaitu berada pada level 3 (defined).

3. Analisis Kesenjangan (Gap Analysis)

Setelah diketahui keadaan aktual mengenai tingkat kematangan saat ini (current maturity) dan juga tingkat kematangan yang ingin dicapai (expected maturity) mengenai pengelolaan, maka tahap selanjutnya adalah analisis kesenjangan (gap analysis). Analisis kesenjangan ini dilakukan untuk mengidentifikasi kegiatan apa saja yang perlu dilakukan oleh pihak pengelola PT Centra Global Investama Jakarta agar keadaan aktual mengenai current maturity bisa mencapai tingkat kematangan yang ingin dicapai. Proses analisisnya adalah setelah mendapatkan nilai tingkat kematangan keadaan saat ini dan tingkat kematangan yang ingin dicapai kemudian menghitung nilai kesenjangan. Rumus menghitung nilai kesenjangan adalah sebagai berikut:

Gap = Expected Maturity - Current Maturity (2)

Nilai kesenjangan digunakan untuk menentukan kebijakan-kebijakan apa saja yang akan diambil untuk perbaikan penggunaan tata kelola teknologi informasi PT Centra Global Investama Jakarta. Sehingga dengan harapan penggunaan teknologi informasi dapat dimanfaatkan lebih baik dari sebelumnya.

Berdasarkan data jumlah maturity level pada domain delivery and support dan domain monitoring and evaluation di atas, maka akan didapatkan current maturity pada setiap index maturity. Setelah di dapatkan current maturity untuk setiap domain delivery and support dan monitoring and evaluation maka akan dapat dijelaskan setiap kendali proses dan dapat diketahui

\begin{tabular}{|c|c|c|c|}
\hline Domain & Proses & $\begin{array}{l}\text { Current } \\
\text { Maturity }\end{array}$ & $\begin{array}{l}\text { Maturity } \\
\text { Level }\end{array}$ \\
\hline DS1 & $\begin{array}{l}\text { Mendefinisikan dan mengelola } \\
\text { tingkat layanan }\end{array}$ & 2.94 & Defined \\
\hline DS2 & $\begin{array}{l}\text { Mengelola pelayanan dari pihak } \\
\text { ketiga }\end{array}$ & 2.96 & Defined \\
\hline DS3 & Mengatur kinerja dan kapasitas & 2.84 & Defined \\
\hline DS4 & $\begin{array}{l}\text { Menjamin keberlangsungan } \\
\text { pelayanan }\end{array}$ & 3.00 & Defined \\
\hline DS5 & Menjamin keamanan sistem & 2.78 & Defined \\
\hline
\end{tabular}
analisis kesenjangan (gap analysis) yang digambarkan pada tabel berikut:

Tabel 4. Rekapitulasi Perbandingan Maturity Level Antara Responden Domain DS 
DS6

Mengidentifikasi dan

Defined

DS7 Memberikan pelatihan dan

2.40

Repeata pendidikan kepada user

ble

DS8 Mengelola service desk dan insiden

$2.89 \quad$ Defined

DS9 Mengatur konfigurasi

$2.64 \quad$ Defined

DS10 Mengatur permasalahan

3.00

Defined

DS11 Mengatur data

$2.23 \quad$ Repeata

DS12 Mengatur lingkungan fisik

2.99 Defined

DS13 Mengatur operasional

2.97

Defined

\begin{tabular}{ccc}
\hline Rata-Rata Indeks & 2.79 & Defined \\
\hline
\end{tabular}

Tabel 5. Rekapitulasi Perbandingan Maturity Level Antara Responden Domain ME

\begin{tabular}{|c|c|c|c|}
\hline Domain & Proses & Current Maturity & Maturity Level \\
\hline DS1 & $\begin{array}{l}\text { Mengawasi dan } \\
\text { mengevaluasi kinerja } \\
\text { teknologi informasi }\end{array}$ & 2.56 & Defined \\
\hline DS2 & $\begin{array}{l}\text { Mengawasi dan } \\
\text { mengevaluasi kontrol } \\
\text { internal }\end{array}$ & 2.32 & Repeatable \\
\hline DS3 & $\begin{array}{l}\text { Menjamin kepatuhan } \\
\text { umum }\end{array}$ & 2.43 & Repeatable \\
\hline \multirow[t]{2}{*}{ DS4 } & $\begin{array}{l}\text { Membuat tata kelola } \\
\text { teknologi informasi }\end{array}$ & 2.51 & Defined \\
\hline & Rata-Rata Indeks & 2.46 & Repeatable \\
\hline
\end{tabular}

Gap antara current maturity dan expected maturity tersebut secara diagram dapat digambarkan sebagai berikut:

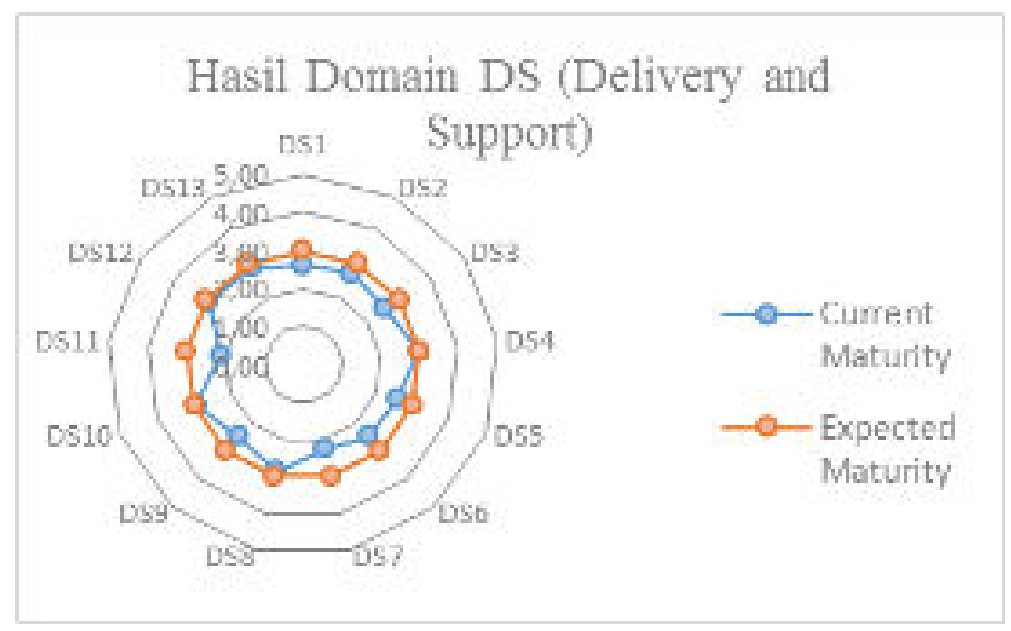

Gambar 2. Current Maturity VS Expected Maturity Pada Domain DS 


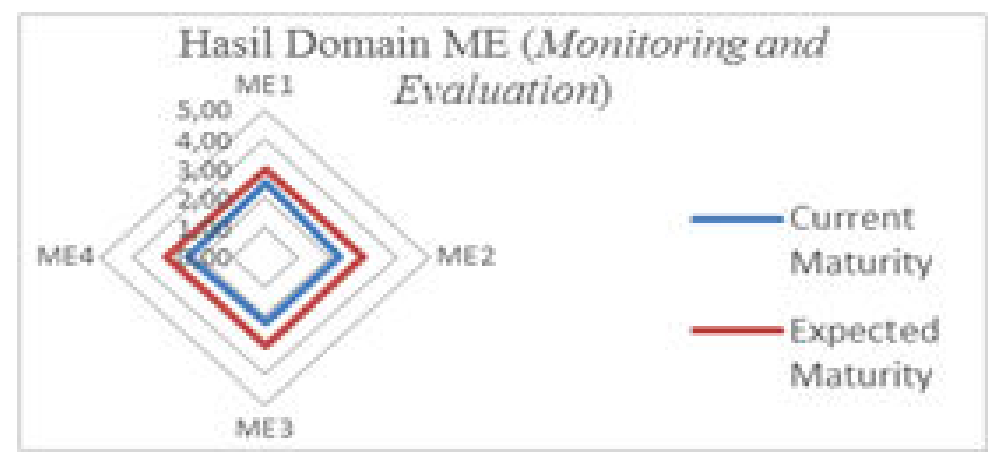

Gambar 3. Current Maturity VS Expected Maturity Pada Domain ME

Setelah diketahui rata-rata indeks dari setiap domain, pengukuran tingkat kematangan tata kelola teknologi informasi pada PT Centra Global Investama Jakarta akan terlihat pada hasil perhitungan rata-rata indeks dari kedua domain yang dijelaskan dengan tabel sebagai berikut:

Tabel 6. Rata-Rata Indeks Maturity Level Domain DS dan ME

\begin{tabular}{lcccc}
\hline Proses & $\begin{array}{c}\text { Current } \\
\text { Maturity }\end{array}$ & Maturity Level & Expected Level & GAP \\
\hline $\begin{array}{l}\text { Rata-rata indeks } \\
\text { domain delivery }\end{array}$ & 2.79 & Defined & 3 & 0.21 \\
$\begin{array}{l}\text { and support } \\
\begin{array}{l}\text { Rata-rata indeks } \\
\text { domain } \\
\text { monitoring and } \\
\text { evaluation }\end{array}\end{array}$ & 2.46 & Repeatable & 3 & 0.54 \\
\hline
\end{tabular}

\section{Rata-Rata}

Indeks DS dan

ME

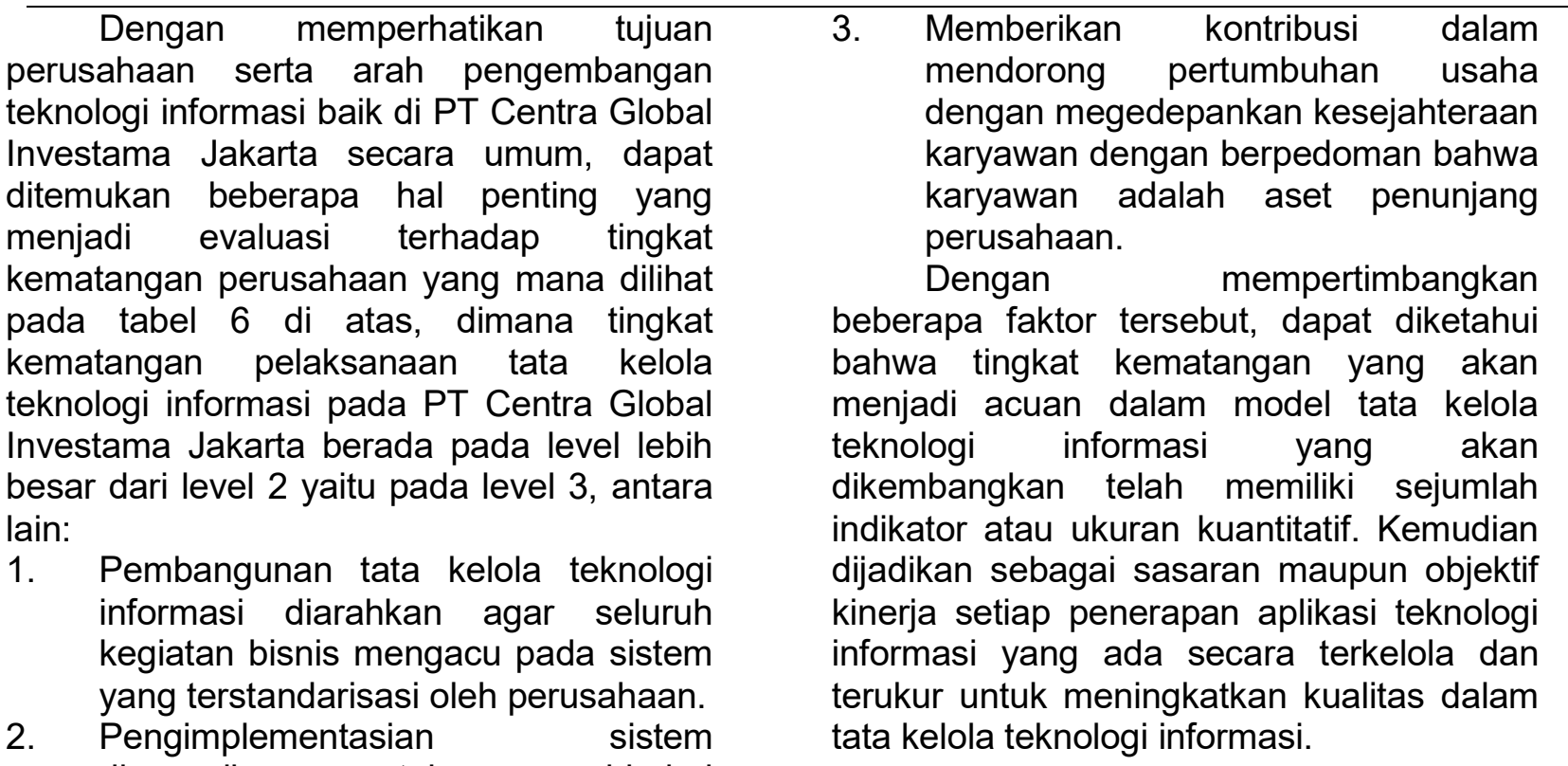

\section{SIMPULAN}

Hasil pengolahan dari tabulasi data, ketimpangan sehingga kegiatan dapat diatur lebih fungsional. rata-rata nilai kematangan untuk PT Centra 
Global Investama Jakarta adalah 2,71. Ini menunjukkan bahwa dalam melaksanakan tata kelola teknologi informasi telah melakukan prosedur yang terstandarisasi, terdokumentasi, dan telah dikomunikasikan melalui pelatihan dan media. Namun masih ditemukan permasalahan pada tingkat pelaksanaan dan kepegawaian yang terlihat pada gap analysis sebesar 0,29 sehingga perlu dilakukan perbaikan-perbaikan agar lebih baik kedepannya. Berdasarkan hasil penelitian dan pembahasan, maksud dan tujuan penelitian, pengolahan data, dan analisa yang telah dilakukan oleh peneliti maka dapat disimpulkan sebagai berikut:

1. Perusahaan sudah baik dalam pengkajian dan evaluasi tata kelola teknologi informasi, terlihat pada hasil maturity level telah mencapai enterprise target pada level 3 . Prosedur telah distandarisasikan, didokumentasikan, serta dikomunikasikan melalui pelatihan. Namun implementasinya diserahkan pada setiap individu, sehingga kemungkinan besar penyimpangan tidak dapat di deteksi. Prosedur tersebut dikembangkan sebagai bentuk formulasi dari praktik yang ada.

2. Terdapat kepercayaan yang cukup tinggi terhadap pengetahuan individu sehingga kemungkinan terjadi error cukup besar. Pengelolaan layanan teknologi informasi PT Centra Global Investama Jakarta belum melewati proses pengawasan yang cukup baik sehingga KPI (Key Performance Indicator) dan KGI (Key Goals Indicator) belum terlaksana dengan baik.

\section{REFERENSI}

[1]

D. A. Kristiyanti, "PENERAPAN METODE WAITING LINE UNTUK EVALUASI PELAYANAN PENJUALAN MERCHANDISE KAMPUS PADA PT. COME INDONUSA JAKARTA," J. Pilar Nusa Mandiri, vol. 1, no. 14, 2018.

[2] R. N. Rifai and Wasilah, "PENGGUNAAN METODE COBIT
FRAMEWORK $4.1 \quad$ DALAM

MENGAUDIT SISTEM INFORMASI AKADEMIK (SIAKAD) PADA IAIN RADEN INTAN LAMPUNG," J. TIM Darmajaya, vol. 1, no. 1, pp. 83-91, 2015.

[3] G. Waluyan and A. D. Manuputty, "Evaluasi Kinerja Tata Kelola TI Terhadap Penerapan Sistem Informasi Starclick Framework COBIT 5 (Studi Kasus: PT. Telekomunikasi Indonesia, Tbk Semarang)," J. Teknol. dan Sist. Inf., vol. 2, no. 3, pp. 157-166, 2016.

[4] H. T. Sihotang, "PENERAPAN TATA KELOLA TEKNOLOGI INFORMASI DENGAN MENGGUNAKAN COBIT FRAMEWORK 4.1 STUDI KASUS PADA PT. PERKEBUNAN NUSANTARA III MEDAN (PERSERO)," J. Mantik Penusa, vol. 17, no. 1, pp. 1-7, 2015.

[5] F. M. Alkhaldi, S. M. Hammami, and M. A. Uddin, "Understating Value Characteristics Toward a Robust IT Governance Application in Private Organizations using COBIT Framework," Int. J. Eng. Bus. Manag., vol. 9, pp. 1-8, 2017.

[6] W. W. Winarno, Sistem Informasi Manajemen, Third. Yogyakarta: UPPS STIM YKPN, 2017.

[7] S. Anas, W. W. Winarno, and H. Al Fatta, "Evaluasi Tata Kelola Teknologi Informasi Akademik STMIK Dipanegara Makassar," J. PPKM, vol. I, pp. 28-33, 2017.

[8] M. Irianto, IT Audit: Audit Berbasis Risiko, 1st ed. Irianto, Mohamad, 2015.

[9] I. P. A. Swastika and I. G. L. A. Raditya Putra, Audit Sistem Informasi dan Tata Kelola Teknologi Informasi, 1st ed. Yogyakarta: CV ANDI OFFSET, 2016.

[10] I. D. Lesmono and D. Erica, "Tata Kelola Teknologi Informasi Dengan Metode COBIT 4 . 1 ( Studi Kasus: PT . IMI )," Kaji. IIm. Univ. Bhayangkara Jakarta Raya, vol. 18, no. 1, pp. 75-84, 2018. 